\title{
ДИАГНОСТИКА ФАКТОРОВ УСТОЙЧИВОСТИ ЭКОНОМИЧЕСКОГО РОСТА БИЗНЕСА
}

\author{
(c) 2020 Байрамкулов Магомед Алиевич \\ студент магистратуры \\ Финансовый университет при Правительстве Российской Федерации, Россия, Москва \\ E-mail: bayramkulov09@gmail.com \\ https://orcid.org/0000-0002-6340-7073 \\ (C) 2020 Байрамуков Локман Хусеинович \\ студент магистратуры \\ Финансовый университет при Правительстве Российской Федерации, Россия, Москва \\ E-mail: lokman.bayramukov@gmail.com \\ https://orcid.org/0000-0002-7518-8656
}

Предмет/тема. Исследование критериев оценки эффективности деятельности организации, оказывающих влияние на устойчивость её развития. Приоритетной задачей для стабилизации национальной экономики выступает обеспечение устойчивости развития компаний.

Цели/задачи. Выявление особенностей устойчивости экономического роста бизнеса и проведение анализа влияющих на него факторов в деятельности организации. Были поставлены следующие задачи: раскрытие сущности и содержания экономического роста организации; исследование классической модели устойчивого экономического роста; определение влияния современных концепций управления на подходы к оценке устойчивости экономического роста бизнеса; идентификация ключевых факторов устойчивости экономического роста организации в современных условиях; анализ зрелости устойчивого развития; обоснование стратегии устойчивого развития

Методология. В процессе исследования были применены методы теоретического исследования, анализ и синтез, группировка и сравнение, системный и комплексный подходы.

Результаты/выводы. В ходе проведения исследования были раскрыты теоретические аспекты устойчивого развития бизнеса, раскрыта сущность факторов, оказывающих влияние на данный процесс, была представлена классификация уровней зрелости организации и методология работы с ней, были представлены условия, необходимые для устойчивого развития бизнеса.

Ключевые слова: диагностика, бизнес, устойчивое развитие, факторы, стейкхолдеры, заинтересованные лица, социальная ответственность организации, прибыль и рентабельность, пути повышения эффективность организации, управление бизнесом, устойчивый экономический рост, экологические и социальные аспекты ведения бизнеса.

Достижение устойчивого экономического роста бизнеса является одной из ключевых задач, стоящих перед руководителями современных организаций. Для создания основы устойчивого развития бизнеса необходимо проводить постоянный комплексный анализ всех воздействующих на компанию факторов и оценивать их влияние на развитие предприятия.

Устойчивым может быть экономический рост, рассматриваемый в единстве с экологическими и социальными аспектами, отражающий эффективность управления, экологическую ответственность и корпоративную социальную ответственность.
Предпринимательская деятельность весьма динамична, любая компания, независимо от размера, вида деятельности и множества других характеристик, растет и развивается с учетом изменений внутренней и внешней среды.

Различные проявления динамики бизнеса можно наблюдать в период существования деятельности экономического субъекта. Большая часть динамических процессов характеризируется либо ростом, либо развитием. Рост -увеличение масштабов бизнеса (рост стоимости, доли рынка, объемов реализации). Развитие - это качественное изменение (выход на новые рынки, изменение технологии производства, обеспечи- 
вающее долгосрочное конкурентное преимущество).

Экономический рост организации тесно связан с увеличением экономического потенциала компании. В его состав включают финансовый, инновационный, технологический (производственный), кадровый (трудовой) и управленческий потенциал.

Увеличение финансового потенциала характеризуется способностью компании накапливать финансовые резервы для реализации инвестиционных проектов. Этот процесс происходит вместе с ростом прибыли организации, а также за счет внешних источников.

Рост инновационного и технологического (производственного) потенциала связан с увеличением используемого основных и оборотных средств, внедрением более совершенных технологий, расширением выпуска товаров или услуг.

Увеличение кадрового потенциала зависит от количества трудовых ресурсов, используемых организацией, уровня профессиональных знаний, накопленного опыта, а также повышения их квалификации.

Рост управленческого потенциала - это расширение возможностей менеджеров компании, способность каждого управленческого работника принимать эффективные решения в пределах своей компетенции.

Формирование и развитие экономического потенциала хозяйствующего субъекта обеспечивается за счет привлечения, наращивания и укрепления соответствующих ресурсов. Чем большей ресурсной базой обладает предприятие, и чем лучше она соответствует его целям и задачам, тем сильнее его экономический потенциал. Следовательно, рост потенциала - это преимущество организации, которое необходимо эффективно использовать.

Экономический рост организации базируется на сочетании экстенсивных и интенсивных факторов. Интенсивные способствуют росту конечных результатов, то есть количества производимой продукции, при этом величина самих ресурсов остается неизменной (или наблюдается незначительный рост). Экстенсивные представляют собой увеличение производства за счет простого количественного расширения самих факторов производства, например увеличения числа работников без повышения квалификации, рост капиталовложений без улучшения технологий.
Интенсивный рост можно достичь при более эффективном использовании ресурсов (человеческих ресурсов, капитала, материальных и нематериальных активов) имеющихся у компании. Экстенсивный рост возможен за счет наращивания ресурсов, а не за счет повышения эффективности труда.

Измерителями экономического роста могут выступать следующие показатели: рост выручки, рост прибыли, рост стоимости бизнеса. Рост, как правило, носит количественный характер и может быть обратим. Отклонение от порогового ведет к кризису.

Для того чтобы динамика бизнеса была устойчивой необходима стратегия, которая определяет стратегические цели организации и может сформулировать желаемое состояние по завершению планируемого периода. Различают такие стратегии, как: интегрированный рост; концентрированный рост; франчайзинг; диверсификация.

Основным инструментом обеспечения роста и развития организации являются инвестиции и инновации. Для них характерны такие признаки, как: вложение капитала в новые продукты, оборудование, бизнес и подобные объекты в целях получения дохода в будущем. В современном бизнесе инвестиции и инновации должны существовать вместе. Так, например, без вложения средств (инвестиций) невозможно разработать и вывести на рынок новый продукт (внедрить продуктовую инновацию), также, как и от внедрения новой технологии обработки материалов (технологическая инновация) возможна экономия средств для вложения (инвестирования) в новое оборудование.

При сочетании высокой инновационной готовности организации, с учетом специфики формирования потенциала её роста можно предположить, что комплексная реализация инновационно-инвестиционных проектов может стать источником устойчивого экономического роста.

Динамика развития организации, в первую очередь, должна быть сбалансированной. В модели сбалансированного роста Р.Марриса ключевым критерием экономического роста хозяйствующего субъекта выступает увеличение объема продаж. Добиться сбалансированного роста поможет взвешенная финансовая политика, основанная на следующих характеристиках: коэффициент сохранения прибыли; коэффици- 
ент задолженности или уровень долговой нагрузки; коэффициент текущей ликвидности.

Принципы устойчивого развития, согласно Всемирной комиссии по проблемам защиты окружающей среды и развитию (WCED):

1) справедливость распределения преимуществ и затрат, связанных с использованием природных ресурсов и окружающей среды между странами, богатыми и бедными, настоящим и будущими поколениями.

2) повышать качество жизни человека. Экономический рост как таковой (рост материального благосостояния) - не самоцель развития.

3) сохранить жизнеспособность и разнообразие всего живого на Земле, возможность к самостоятельному возобновлению экологических систем.

4) минимизировать использование не возобновляемых ресурсов путем вторичной переработки и ресурсосберегающих технологий.

5) развитие в пределах потенциальной емкости экологических систем Земли.

6) стимулировать социальную заинтересованность общества в сохранении среды его обитания (поощрения, ограничения, запреты и наказания).

7) интеграция процессов социальноэкономического развития и охраны окружающей среды, баланс интересов в трех сферах.

8) способствовать достижению единства действий на мировом уровне.

В конце XX - начале XXI в. экономисты стали рассматривать идеи устойчивого развития на уровне территорий и отдельных хозяйствующих субъектов.

Концепция устойчивого развития на уровне экономических субъектов предполагает необходимость взаимосвязанного рассмотрения экологической, социальной и экономической сфер деятельности организации (ESG), в том числе: экологическая; социальная; экономическая.

Концепция устойчивого развития связана с рядом управленческих концепций, которые получили широкое применение в практике корпоративного менеджмента.

Устойчивое развитие организации обусловливается взаимосвязанными действиями, направленными на достижение сбалансированного социально-экономического и экологического эффекта и способствующими переходу в качественно новое состояние экономического субъекта, формирующего и регулирующего отношения с заинтересованными пользователями (стейкхолдерами).

Ключевым моментом теории стейкхолдеров является то, что бизнес-цели гораздо шире, чем определение прибыли или богатства для их владельцев, они должны учитывать интересы не только самих собственников, но и гораздо более широкого круга заинтересованных лиц.

Когда организации учитывает требования и интересы стейкхолдеров это приводит к повышению уровня доверия этих сторон, что в свою очередь способствует формированию так называемого капитала отношений и создает необходимые, но недостаточные условия устойчивого развития экономического субъекта.

Стейкхолдеры оказывают существенное влияние на результаты деятельности организации, так как определяются ее доступом к различным ресурсам. После определения интересов основных групп заинтересованных сторон компании выбираются показатели для определения того, достигнуты значения ключевых показателей для каждой группы стейкхолдеров.

Степень удовлетворенности интересов всех этих разнородных групп потребителей (экономических, социальных, экологических) определяет долгосрочную стабильность общества, способствуя тем самым формированию долгосрочной стоимости организации.

Экономический рост является неотъемлемой частью устойчивого развития организации. Экономический рост компании проявляется в количественном улучшении состояния хозяйствующего субъекта, а развитие еще и в качественном.

Для анализа и оценки показателей, характеризующих устойчивость экономического роста организаций, существуют классические модели Кобба-Дугласа, Р. Марриса, Р. Хиггинса, Дж. Ван Хорна, Р. Визванатана.

Также разработаны концепции для оценки устойчивости экономического роста организации. Концепция устойчивого развития на уровне экономических субъектов предполагает необходимость взаимосвязанного рассмотрения экологической, социальной и экономической сфер деятельности организации (ESG). Концепция устойчивого развития связана с рядом управленческих концепций, которые получили широкое применение в практике корпоративного контроля. В том числе стейкхолдерская 
концепция, концепция корпоративной социальной ответственности.

Для создания основы устойчивого развития бизнеса необходимо проводить постоянный комплексный анализ всех воздействующих на компанию факторов и оценивать их воздействие на развитие предприятия.

Необходимо оценить воздействие на примере определенной компании. Общество с ограниченной ответственностью «АБС» осуществляет оптовую торговлю фармацевтическими препаратами. Компания занимает 0,2864\% (5,08 млрд. руб.) рынка страны «Торговля оптовая фармацевтической продукцией». Общий объем рынка составляет 1.77 трлн. руб., за 2018 год.

Дополнительными видами деятельности являются: производство лекарственных препаратов и материалов, применяемых в медицинских целях; розничная торговля лекарственными средствами в специализированных магазинах (аптеках); деятельность по складированию и хранению; технические испытания, исследования, анализ и сертификация; деятельность по техническому контролю, испытаниям и анализу; научные исследования и разработки в области естественных и технических наук; исследование конъюнктуры рынка.

ООО «АБС» - международная фармацевтическая компания. На протяжении многих лет ООО «АБС» успешно разрабатывает эффективные методы помощи пациентам в разных областях. Организация развивает партнерские отношения с ведущими научными организациями по всему миру, что позволяет ей находить решения самых насущных проблем здоровья и удовлетворять самые неотложные медицинские потребности граждан.

Основные показатели финансовой отчётности ООО «АБС» за 2019 год:

1) собственный капитал - 3462935 тыс. руб.;

2) д доходы -5168645 тыс. руб.;

3) расходы - 4991120 тыс. руб.;

4) чистая прибыль -42215 тыс. руб.

Роль нефинансовой информации всё больше возрастает при принятии решений инвесторами. В основном эта информация связана с ESG-факторами. Они представляют собой группу экологических, социальных и управленческих факторов. В настоящее время основным источником информации о ESG-факторах организации является публичная нефинансовая отчетность (отчеты об устойчивом развитии, интегриро- ванные отчеты, экологические, социальные отчеты). Раскрытие целого комплекса ESG-факторов можно наблюдать, например, в стандартах отчетности в области устойчивого развития GRI. В каждой серии GRI Standards раскрываются свои аспекты, относящиеся к ESG-факторам: 200 (экономические темы), 300 (экологические темы) и 400 (социальные темы).

Практика подготовки и раскрытия нефинансовой информации российскими компаниями находится на стадии формирования. Все необходимые данные, которые могут получить заинтересованные пользователи, отражаются в нефинансовом отчете. Инструментом оценки устойчивости развития выступает нефинансовая отчетность. Так как ООО «АБС» относится к среднему бизнесу, такой отчет в компании не составляется. Но, как и большинство российских экономических субъектов, ООО «АБС» стремится к повышению информированности инвесторов, кредитных организаций, поставщиков и покупателей об основных аспектах своей деятельности путем представления достоверной, содержательной и оперативной информации. Поэтому наряду с обязательной отчетностью ООО «АБС» ведет раздел на сайте посвященный благотворительной деятельности и вопросам взаимодействия с персоналом, который называется «Социальная ответственность».

Корпоративная социальная ответственность играет важнейшую роль при принятии управленческих решений в компании и является неотъемлемой частью всей деятельности компании. Социальная ответственность - ключевая часть стратегии и ведения бизнеса ООО «АБС».

Также нельзя не отметить реализацию многочисленных социальных программ, которые осуществляет ООО «АБС», они являются неотъемлемой частью КСО.

Компания использует два инструмента реализации своих социальных проектов: благотворительные проекты и спонсорская помощь; корпоративное волонтерство.

Рассмотрим абсолютные показатели финансовой отчетности ООО «АБС», они характеризуют обеспеченность запасов источниками их формирования. Излишек или недостаток источников является обобщающим показателем финансовой устойчивости.

Помимо абсолютных, финансовую устойчивость характеризует относительные показатели. Такие коэффициенты могут охарактеризовать, 
насколько компания зависима от кредиторов и внешних инвесторов. В таблице 1 представлен расчет относительных показателей финансовой устойчивости ООО «АБС» за период 2018-2019 гг.

Таким образом, анализ данных показателей свидетельствует о том, что в динамике за период 2018-2019 гг. финансовое положение ООО «АБС» улучшается. Наиболее полно финансовую устойчивость компании характеризует коэффициент соотношения собственного и заемного капитала, его значение в 2019 году возросло на 40,31\% по сравнению с предыдущим годом, что является положительной тенденцией.

Для более объективной оценки, наряду с этим показателем был рассчитан коэффициент автономии (финансовой независимости). Его нормативное значение: >0,6. За весь анализируемые период значения превысили норматив. Доля владельцев компании в общей сумме средств, вложенных в ООО «АБС», выросла на 9,31\% в 2019 году. Рост данного показателя говорит о том, что организация становится более финансово устойчива и более независима от внешних кредиторов.

Коэффициент финансовой зависимости показал, что доля привлеченных средств в 2018 году составляла 0,3 в общей сумме средств, а в
2019 году сократилась на 22\% и стала равна 0,23. Нормативное значение данного показателя: $<0,4$. Тенденция снижения является положительной и находится в рамках норматива.

Коэффициент текущей задолженности также сократился на 22\% в 2019 году. Рекомендуемое значение: <0,3. В 2018 году значение показателя было равно нормативу, в 2019 году наблюдается сокращение, что говорит о снижении задолженности в общем объеме средств.

Значения коэффициента финансового риска говорят о том, что на 1 руб. вложенных в активы собственных средств приходится 0,42 руб. привлеченных средств в 2019 году и 0,30 руб. в 2018 году. Нормативное значение показателя: <1. В отчетном периоде произошло снижение данного коэффициента на 28\%, что говорит о сокращении зависимости ООО «АБС» от привлечения заемных средств.

Небольшое снижение (на 0,75\%) коэффициента маневренности характеризует замедление движения собственного капитала за счет доли оборотного капитала, обладающего наибольшей ликвидностью. Чем выше значение показателя, тем выше финансовая устойчивость организации. Несмотря на это отклонение, оно не оказало большого влияние на общую финансовую

Таблица 1. Относительные показатели финансовой устойчивости ООО «АБС» за 2018-2019 гг. / [Relative indicators of financial stability of ABS for 2018-2019]

\begin{tabular}{|l|c|l|c|c|c|c|}
\hline \multicolumn{1}{|c|}{$\begin{array}{c}\text { Наименование } \\
\text { показателя }\end{array}$} & $\begin{array}{c}\text { Условное } \\
\text { обозначе- } \\
\text { ние }\end{array}$ & \multicolumn{1}{|c|}{ Формула } & 2017 г. & $\begin{array}{c}\text { Абсо- } \\
\text { лютное } \\
\text { отклоне- } \\
\text { ние }\end{array}$ & $\begin{array}{c}\text { Темп } \\
\text { динами- } \\
\text { ки, \% }\end{array}$ \\
\hline $\begin{array}{l}\text { Коэффициент автономии } \\
\text { минансовой независи- } \\
\text { мости })\end{array}$ & $\mathrm{K}_{\mathrm{A}}$ & $\begin{array}{l}\text { Собственный капитал/ } \\
\text { Валюта баланса }\end{array}$ & 0.70 & 0.77 & 0.07 & 109.31 \\
\hline $\begin{array}{l}\text { Коэффициент финансо- } \\
\text { вой зависимости }\end{array}$ & $\mathrm{K}_{\text {Ф3 }}$ & $\begin{array}{l}\text { Заемный капитал/Валю- } \\
\text { та баланса }\end{array}$ & 0.30 & 0.23 & -0.07 & 77.91 \\
\hline $\begin{array}{l}\text { Коэффициент текущей } \\
\text { задолженности }\end{array}$ & $\mathrm{K}_{\text {Тз }}$ & $\begin{array}{l}\text { Краткосрочные обяза- } \\
\text { тельства/Валюта баланса }\end{array}$ & 0.30 & 0.23 & -0.07 & 77.91 \\
\hline $\begin{array}{l}\text { Коэффициент финансо- } \\
\text { вого риска (левериджа) }\end{array}$ & $\mathrm{K}_{\text {ФР }}$ & $\begin{array}{l}\text { Заемный капитал/Соб- } \\
\text { ственный капитал }\end{array}$ & 0.42 & 0.30 & -0.12 & 71.27 \\
\hline $\begin{array}{l}\text { Коэффициент маневрен- } \\
\text { ности }\end{array}$ & $\mathrm{K}_{\mathrm{M}}$ & $\begin{array}{l}\text { Крборотные активы- } \\
\text { Краткосрочные обяза- } \\
\text { тельства)/Собственный } \\
\text { капитал }\end{array}$ & 0.97 & 0.96 & -0.01 & 99.25 \\
\hline $\begin{array}{l}\text { Коэффициент обеспе- } \\
\text { ченности собственными } \\
\text { оборотными средствами }\end{array}$ & $\mathrm{K}_{\text {Сос }}$ & $\begin{array}{l}\text { Оборотные активы- } \\
\text { Краткосрочные обяза- } \\
\text { тельства/Оборотные } \\
\text { активы }\end{array}$ & 0.70 & 0.76 & 0.07 & 109.33 \\
\hline $\begin{array}{l}\text { Коэффициент соотно- } \\
\text { шения собственного и } \\
\text { заемного капитала }\end{array}$ & КС & $\begin{array}{l}\text { Собственный капитал/ } \\
\text { Заемный капитал }\end{array}$ & 2.37 & 3.33 & 0.96 \\
\hline
\end{tabular}

Источник: Составлено авторами 
устойчивость ООО «АБС.

Коэффициент долгосрочного привлечения заёмных средств и коэффициент структуры привлеченного капитала не удалось рассчитать, так как у организации отсутствуют долгосрочные обязательства за весь анализируемый период.

Значения коэффициента обеспеченности собственными оборотными средствами иллюстрируют, что доля собственных оборотных средств в 2018 году составила 0,70 в общей величине средств, а в 2019 году 0,70 . Значение показателя увеличилось на 9,33\%, что является положительной тенденцией.

Эффективность функционирования бизнеса характеризуется качественными и количественными показателями деловой активности. К качественным относят деловую репутацию, расширение рынков сбыта, конкурентоспособность товаров.

Количественную оценку можно провести по двум направлениям: исследование динамики и соотношения темпов роста выручки, прибыли и средней величины активов; изучение относительных показателей, которые характеризуют степень эффективности использования ресурсов.

Первое направление предполагает собой оценку оптимального соотношения, которые называется «золотое правило экономики».

Для определения трех групп неравенств, рассчитаем темпы роста соответствующих показателей. В таблице 2 представлены темпы роста показателей, необходимых для оценки соотношения «золотого правила экономики» ООО «АБС» за 2018-2019 гг.

Таким образом, полученные значения подставим в неравенство и получим следующий результат:

$58.37 \%<100.02 \%>93.60 \%<100 \%$

Соотношение $\mathrm{T}_{\text {чп }}>\mathrm{T}_{\mathrm{B}}$ не выполняется, что говорит об увеличении издержек. Себестоимость в 2019 году выросла, что и стало причиной полученных результатов.

Вторая часть неравенства $\mathrm{T}_{\mathrm{B}}>\mathrm{T}_{\mathrm{A}}$ выполне- на, это свидетельствует о росте эффективности использования ресурсов, повышается отдача с каждого рубля, вложенного в организацию.

Соотношение $\mathrm{T}_{\mathrm{A}}>100 \%$ не выполняется, значит происходит сокращение активов и капитала.

В целом деловая активность ООО «АБС» в 2019 году снизилась по сравнению с предыдущим годом. Коэффициент оборачиваемости активов составил 1.13 , он увеличился на 0.08 или на 8\% в 2019 году, что говорит о более интенсивном использовании ресурсов, об увеличении скорости оборота средств организации.

Коэффициент оборачиваемости собственного капитала 1.47, он стал меньше на 0.02 или $1,2 \%$ в отчетном периоде, то есть скорость оборота собственных средств замедлилась. Значение данного показателя сигнализирует о недостаточно эффективном использовании ресурсов.

Отдача внеоборотных активов в 2019 году составила 40.62 руб. проданной продукции от каждого рубля внеоборотных активов, что на 10.9 или на 21\% меньше, чем в 2018 году. Такая тенденция является отрицательной, так как интенсивность использования основных средств и иных внеоборотных активов снизилась.

Коэффициент оборачиваемости оборотных активов показывает, что в 2019 году на 1 руб. оборотных активов приходится 1,16 руб. выручки. Показатель вырос на 0.09 или на 8\% по сравнению с предыдущим годом и положительно повлиял на деловую активность в целом.

Период обращения запасов вырос на $12 \%$ в 2019 году и стал составлять 108 дней. Такое увеличение свидетельствует об относительном перенакоплении запасов или сложностях со сбытом товаров.

Период погашения дебиторской задолженности сократился на 23\% в 2019 году. Оплата проданных товаров и осуществление погашения прочей дебиторской задолженности стали происходить на 51 день быстрее (170 дней), но не соответствует оптимальному значению (до 30 дней)

Продолжительность операционного цикла

Таблица 2. Темпы роста абсолютных показателей 000 «АБС» / [Growth rates of absolute indicators of ABS LLC]

\begin{tabular}{|l|c|c|c|}
\hline \multicolumn{1}{|c|}{ Наименование показателя } & 2018 г. & 2019 г. & Темп роста, \% \\
\hline Чистая прибыль, тыс. руб. & 72316 & 42215 & 58.37 \\
\hline Выручка, тыс. руб. & 5075134 & 5076268 & 100.02 \\
\hline Средняя величина активов & 5002801 & 4682829 & 93.60 \\
\hline
\end{tabular}

Источник: составлено авторами 
в 2019 году меньше на 39 дней или на 12\% чем в 2018 году. Иными словами, с момента поступления товарно-материальных ценностей до момента получения оплаты за проданные товары проходит, в общем, 278 дней. Тенденция снижения является положительной, но всё равно составляет довольно длительный период, но в данном случае необходимо учитывать специфику деятельности, так как лекарственные препараты, которые реализует ООО «АБС» достаточно дорогостоящие.

Период погашения кредиторской задолженности сократился на 53 дня в 2019 году и составил 121 день. Такое изменение может носит положительный характер, сократилось время, в течение которого в среднем производится погашение обязательств. Но значение также далеко от оптимального (30 дней).

Продолжительность финансового цикла увеличилась на 9\% и составила 157 дней, что говорит об увеличении времени участия инвестированного капитала в финансировании операционного цикла.

Для оценки финансовой результативности ООО «АБС» используем метод финансовых коэффициентов, а именно рассчитаем показатели рентабельности. В таблице 3 представлены результаты проведённого анализа за 2018-2019 гг.

Таким образом, финансовая результативность ООО «АБС» снизилась в 2019 году, об это свидетельствует сокращение всех анализируемых коэффициентов рентабельности.
Рентабельность продаж сократилась на 5.20 руб. или на 55\%. В 2019 году 4.22 руб. прибыли приходилось на рубль проданной продукции. Рентабельность продаж можно наращивать путем снижения затрат или же увеличивать реализацию тех товаров, которые востребованы на рынке.

Бухгалтерская рентабельность продаж показывает снижение уровня прибыли до выплаты налога на прибыль на рубль выручки на 1.6 руб. или на $23 \%$ в отчетном периоде по сравнению с предыдущим и составляет 3,5.

Чистая рентабельность продаж в 2019 году сократилась на 0.59 или на $41 \%$. Так, в 2018 году на 1 руб. выручки приходилось 1,42 руб. чистой прибыли, а в 2019 году стало всего 0,83 руб.

Значения рентабельности активов свидетельствуют о снижении эффективности использования ресурсов ООО «АБС». Данные показатель является наиболее информативным для оценки результатов деятельности бизнеса, поэтому необходимо принимать меры по ее повышению, например сокращать себестоимость.

Рентабельность собственного капитала сократилась на $42 \%$ в 2019 году и составила 1.23 . Такой результат говорит о снижении эффективности использования собственного капитала.

Валовая рентабельность в 2019 году составила 31.56, что ниже почти на $20 \%$ значения в 2018 году. На 1 руб. выручки в отчётном периоде стало приходиться меньше на 7,86 руб. валовой прибыли.

Таблица 3. Коэффициенты рентабельности ООО «АБС» за 2018-2019 гг./ [Profitability ratios of ABS LLC for 2018-2019]

\begin{tabular}{|c|c|c|c|c|c|c|}
\hline $\begin{array}{c}\text { Наименование показа- } \\
\text { теля }\end{array}$ & $\begin{array}{l}\text { Условное } \\
\text { обозначе- } \\
\text { ние } \\
\end{array}$ & Формула & 2018 г. & 2019 г. & $\begin{array}{l}\text { Измене- } \\
\text { ние }\end{array}$ & $\begin{array}{c}\text { Темп } \\
\text { роста, \% }\end{array}$ \\
\hline Рентабельность продаж & $\mathrm{R} 1$ & $\begin{array}{l}\text { Прибыль от продаж/ } \\
\text { Выручка }\end{array}$ & 9.42 & 4.22 & -5.20 & 44.78 \\
\hline $\begin{array}{l}\text { Бухгалтерская рента- } \\
\text { бельность продаж }\end{array}$ & $\mathrm{R} 2$ & $\begin{array}{l}\text { Прибыль до налогообложе- } \\
\text { ния/Выручка }\end{array}$ & 4.56 & 3.50 & -1.06 & 76.70 \\
\hline $\begin{array}{l}\text { Чистая рентабельность } \\
\text { продаж }\end{array}$ & R3 & Чистая прибыль/Выручка & 1.42 & 0.83 & -0.59 & 58.36 \\
\hline Рентабельность активов & $\mathrm{R} 4$ & $\begin{array}{l}\text { Чистая прибыль/Средняя } \\
\text { стоимость активов }\end{array}$ & 1.45 & 0.90 & -0.54 & 62.36 \\
\hline $\begin{array}{l}\text { Рентабельность соб- } \\
\text { ственного капитала }\end{array}$ & $\mathrm{R} 5$ & $\begin{array}{l}\text { Чистая прибыль/Средняя } \\
\text { стоимость собственного } \\
\text { капитала }\end{array}$ & 2.14 & 1.23 & -0.91 & 57.40 \\
\hline Валовая рентабельность & R6 & Валовая прибыль/Выручка & 39.42 & 31.56 & -7.86 & 80.06 \\
\hline Затратоотдача & $\mathrm{R} 7$ & $\begin{array}{l}\text { Прибыль от продаж/ (Себе- } \\
\text { стоимость + Ком. расходы + } \\
\text { Управ. расходы) }\end{array}$ & 10.40 & 4.40 & -5.99 & 42.35 \\
\hline
\end{tabular}

Источник: составлено авторами 
Для внешней оценки результативности финансово-хозяйственной деятельности бизнеса важно оценить показатель затратоотдачи, его расчет показал, что в 2019 году на 1 руб. затрат приходится 4,4 руб. прибыли от продаж, что на 6 руб. или на 57,65\% меньше, чем в 2018 году. Такая тенденция к снижению является отрицательной.

Обобщающим показателем результативности бизнеса выступает прибыль до налогообложения, его главной составляющей является прибыль от основной деятельности, ее подвергают особому анализу. Изменение прибыли от продаж продукции, товаров, работ, услуг зависит от многих факторов. По сути, все эти факторы воздействуют на финансово-хозяйственную деятельность организации. В таблице 4 представлены показатели, формирующие прибыль от продаж за 2018-2019 гг. ООО «АБС»

На основании этих данных получаем аддитивную модель:

$$
\text { Пп }=\mathrm{B}-\mathrm{C} / \mathrm{c}-\mathrm{Kp}-\mathrm{yp}
$$

Методом цепных подстановок определим влияние факторов на изменение прибыли (убытка) от продаж:

$\Pi_{0}=\mathrm{B}_{2018}-\mathrm{C} / \mathrm{c}_{2018}-\mathrm{Kp}_{2018}-\mathrm{yp}_{2018}=$ 477912 тыс. руб.

$\Pi_{\text {усл1 }}=\mathrm{B}_{2019}-\mathrm{C} / \mathrm{c}_{2018}-\mathrm{Kp}_{2018}-\mathrm{yp}_{2018}=$ 479046 тыс. руб.

Ппусл2 $=\mathrm{B}_{2019}-\mathrm{C} / \mathrm{c}_{2019}-\mathrm{Kp}_{2018}-\mathrm{yp}_{2018}=$ 79248 тыс. руб.

ППусл3 $=\mathrm{B}_{2019}-\mathrm{C} / \mathrm{c}_{2019}-\mathrm{Kp}_{2019}-\mathrm{Vp}_{2018}=$ 186672 тыс. руб.

$\Pi_{\Pi 1}=\mathrm{B}_{2019}-\mathrm{C} / \mathrm{c}_{2019}-\mathrm{Kp}_{2019}-\mathrm{yp}_{2019}=$ 214048тыс. руб.

1) Влияние величины выручки на прибыль (убыток) от продаж:

$\Delta \Pi_{(\mathrm{B})}=479046-477912=+1134$ тыс. руб.

2) Влияние себестоимости от продаж на изменение прибыли от продаж:

$$
\Delta \Pi \Pi_{(\mathrm{C} / \mathrm{c})}=79248-479046=-399798 \text { тыс. } \text { руб. }
$$

3) Влияние коммерческих расходов на прибыль(убыток) от продаж:

$$
\Delta \Pi_{(\text {Кр) }}=186672-79248=+107424 \text { тыс. руб. }
$$

4) Влияние величины управленческих расходов на изменение прибыли(убытка) от продаж:

$$
\Delta \Pi_{(\mathrm{yp})}=214048-186672=+27376 \text { тыс. руб. }
$$

Таким образом, прибыль от продаж ООО «АБС» сократилась на 263864 тыс. руб., или на $55,21 \%$, на данное изменение оказали влияние следующие факторы:

- Увеличение выручки на $0.02 \%$ повлекло за собой рост прибыли от продаж на 1134 тыс. руб.

- Увеличение себестоимости продаж на 13\% вызвало серьезное падение прибыли от продаж, показатель сократился на 399798 тыс. руб.

- Снижение величины коммерческих и управленческих расходов на 9,29\% и 7,47\% соответственно, позволили скорректировать показатель снижения прибыли от продаж. Так за счет изменения величины коммерческих расходов, прибыль от продаж увеличилась на 107424 тыс. руб., а сокращение управленческих расходов вызвало увеличение прибыли от продаж на 27376 тыс. руб.

В целом снижение прибыли от продаж в 2019 году обуславливается превышением темпов роста себестоимости реализуемой продукции (работ, услуг) над темпами роста выручки от их реализации, даже несмотря на сокращение накладных расходов.

В 2019 и 2018 годах распределения прибыли не производилось. В учетно-аналитической практике возможности компании по расширению основной деятельности за счет реинвестирования собственных средств определяются с помощью коэффициента устойчивости экономического роста. Влияние распределительной

Таблица 4. Влияние факторов на прибыль от продаж ООО «АБС» за 2018-2019 гг. / [Influence of factors on profit from sales of ABS LLC for 2018-2019]

\begin{tabular}{|l|c|c|c|c|c|}
\hline \multicolumn{1}{|c|}{ Показатель } & $\begin{array}{c}\text { Условное } \\
\text { обозначение }\end{array}$ & $\begin{array}{c}2018 \text { г. } \\
\text { тыс. руб. }\end{array}$ & $\begin{array}{c}2019 \text { г. } \\
\text { тыс. руб. }\end{array}$ & $\begin{array}{c}\text { Абсолютное } \\
\text { тыс. руб. }\end{array}$ & Темп роста, \% \\
\hline Выручка & $\mathrm{B}$ & 5075134 & 5076268 & +1134 & 100.02 \\
\hline Себестоимость продаж & $\mathrm{C} / \mathrm{c}$ & 3074509 & 3474307 & +399798 & 113.00 \\
\hline Коммерческие расходы & $\mathrm{Kp}$ & 1156154 & 1048730 & -107424 & 90.71 \\
\hline Управленческие расходы & $\mathrm{Ур}$ & 366559 & 339183 & -27376 & 92.53 \\
\hline Прибыль (убыток) от продаж & Пп & 477912 & 214048 & -263864 & 44.79 \\
\hline
\end{tabular}


политики на устойчивость экономического роста можно определить через оценку влияния факторов, отражающих эффективность финансовохозяйственной деятельности, на степень устойчивого развития ООО «АБС». Воспользуемся факторной моделью вида:

$$
\mathrm{K}_{\text {ур }}=\mathrm{K}_{\mathrm{P}} \times \mathrm{P}_{\Pi} \times \mathrm{K}_{\mathrm{P}} \times \mathrm{K}_{Ф 3}
$$

где $\mathrm{K}_{\text {РП }}$ - коэффициент реинвестирования прибыли, который позволяет оценить текущую политику распределения прибыли компании;

$\mathrm{P}_{\Pi}-$ рентабельность реализованной продукции;

Кр - ресурсоотдача;

$\mathrm{K}_{\Phi 3}$ - коэффициент финансовой зависимости.

Модель отражает воздействие как производственной (второй и третий факторы), так и финансовой (первый и четвертый факторы) деятельности компании на коэффициент устойчивости экономического роста.

В таблице 5 представлен расчет показателей, на основе который будет проводиться факторный анализ.

Модель является мультипликативной, поэтому применим метод абсолютных разниц.

- влияние изменения коэффициента реинвестирования прибыли:

$\Delta \mathrm{K}_{\mathrm{PP}}\left(\mathrm{K}_{\mathrm{P}}\right)=\left(\mathrm{K}_{\mathrm{P} 1}-\mathrm{K}_{\text {РП0 }}\right) \times \mathrm{P}_{\Pi 0} \times \mathrm{K}_{\mathrm{P} 0} \times \mathrm{K}_{\text {Ф30 }}=$ $(1-1) \times 0.09 \times 1.04 \times 0.30=0 \%$

- влияние изменения рентабельности реализованной продукции:

$\Delta \mathrm{K}_{\mathrm{PP}}\left(\mathrm{P}_{\Pi}\right)=\mathrm{K}_{\mathrm{P} 1} \times\left(\mathrm{P}_{\Pi 1}-\mathrm{P}_{\Pi 0}\right) \times \mathrm{K}_{\mathrm{P} 0} \times \mathrm{K}_{\text {Ф30 }}=$ $1 \times(0.04-0.09) \times 1.04 \times 0.30=-1.61 \%$

- влияние изменения ресурсоотдачи:

$\Delta \mathrm{K}_{\mathrm{yP}}\left(\mathrm{K}_{\mathrm{P}}\right)=\mathrm{K}_{\mathrm{P} 1} \times \mathrm{P}_{\Pi 1} \times\left(\mathrm{K}_{\mathrm{P} 1}-\mathrm{K}_{\mathrm{P} 0}\right) \times \mathrm{K}_{\text {Ф30 }}=$ $1 \times 0.04 \times(1.13-1.04) \times 0.30=0.10 \%$
- влияние изменения коэффициента финансовой зависимости:

$\Delta \mathrm{K}_{\mathrm{YP}}\left(\mathrm{K}_{Ф 3}\right)=\mathrm{K}_{\mathrm{P} 1} \times \mathrm{P}_{\Pi 1} \times \mathrm{K}_{\mathrm{P} 1} \times\left(\mathrm{K}_{Ф 31}-\mathrm{K}_{\text {Ф30 }}\right)=$ $1 \times 0.04 \times 1.13 \times(0.23-0.30)=-0.31 \%$

- суммарное влияние трех факторов:

$\Delta \mathrm{K}_{\mathrm{yP}}\left(\mathrm{K}_{\mathrm{P}}\right)+\Delta \mathrm{K}_{\mathrm{yP}}\left(\mathrm{P}_{\Pi}\right)+\Delta \mathrm{K}_{\mathrm{yP}}\left(\mathrm{K}_{\mathrm{P}}\right)+\Delta \mathrm{K}_{\mathrm{yP}}\left(\mathrm{K}_{\text {ФЗ }}\right)=$ $0-1.61+0.10-0.31=-1.82 \%$

Таким образом, стабильность реинвестированной прибыли не повлияла на изменение коэффициента устойчивости экономического роста, так как прибыль не распределялась. Сокращение рентабельности реализованной продукции на 55.22\% привело к снижению коэффициента устойчивости экономического роста на 1,61 процентных пункта. Рост ресурсоотдачи на 8\% вызвал увеличение коэффициента устойчивости экономического роста на 0.10 процентных пункта. Снижение коэффициента финансовой зависимости на 22\% привело к сокращению коэффициента устойчивости экономического роста на 0.31 процентных пункта.

Результаты исследования показали, что наибольшее влияние на снижение коэффициента устойчивого развития оказало сокращения значения рентабельности продаж. Соответственно, на основании этого факта можно сделать вывод, что для обеспечения экономического роста в долгосрочной перспективе необходимо увеличивать объем продаж и снижать себестоимость. В 2019 году объем продаж увеличился на 0,02\%, но и себестоимость увеличилась на $13 \%$. Небольшой рост выручки связан с сокращением реализации двух дорогостоящих препаратов, утративших исключительность, продажи в 2019 году стали ниже запланированных из-за конкуренции. Организации следует уделять больше внимания анализу рынка конкурентов.

Для сокращения себестоимости необходимо ввести комплекс мероприятий по более рацио-

Таблица 5. Показатели для факторного анализа устойчивого экономического роста ООО «АБС» за 2018-2019 гг. / [Indicators for factor analysis of sustainable economic growth of ABS LLC for 2018-2019]

\begin{tabular}{|l|c|c|c|c|}
\hline \multicolumn{1}{|c|}{ Показатель } & 2018 г. & 2019 г. & $\begin{array}{c}\text { Абсолютное } \\
\text { отклонение }\end{array}$ & $\begin{array}{c}\text { Темп роста, } \\
\%\end{array}$ \\
\hline Коэффициент реинвестирования прибыли & 1 & 1 & 0 & 100 \\
\hline Рентабельность реализованной продукции & 0.09 & 0.04 & -0.05 & 44.78 \\
\hline Ресурсоотдача & 1.04 & 1.13 & 0.08 & 108.00 \\
\hline Коэффициент финансовой зависимости & 0.30 & 0.23 & -0.07 & 77.91 \\
\hline Коэффициент устойчивого развития & 2.91 & 1.10 & -1.82 & 37.68 \\
\hline
\end{tabular}


нальному использованию материальных ресурсов, в частности направленных на сокращение энергопотребления. В целом, анализ показал неустойчивую динамику экономического роста в отчетном году. Важно, чтобы коэффициент устойчивого развития был стабилен, для этого необходимо принять меры, описанные выше и стараться держать значения на достигнутом уровне на протяжении долгого времени.

Устойчивое развитие бизнеса требует проведения серьезных контрольных мероприятий со стороны руководства. Управление и контроль невозможно осуществлять без информационноаналитического обеспечения. Для проведения анализа устойчивого развития организации необходимо наличие какой-либо отчетности. Главным критерием, в условиях ограниченности выбора из всех существующих в мире видов отчетности, выступает приближенность структуры отчетности и рассматриваемых активов к концепции устойчивого развития или ее составным элементам. Такая взаимосвязь проявляется в первоначальной направленности разработчиков интегрированной отчетности на создание возможностей для раскрытия информации об устойчивом развитии в корпоративной отчетности экономического субъекта.

Все существенные данные о стратегии компании, показателях ее деятельности, корпоративном управлении и перспективах объединяет интегрированная отчетность таким образом, чтобы они могли отразить экономическое, социальное и экологическое окружение. Данная отчетность дает полное представление о ведении разумного руководства в организации и демонстрирует создание ценности в настоящее время и в перспективе на будущее.

В России интегрированная отчетность на данный момент составляется лишь очень крупным бизнесом, что, безусловно, сужает возможности для наиболее детального анализа. Однако многие организации составляют отчеты о корпоративном управлении или отдельные отчеты об устойчивом развитии, которые также отражают необходимую информацию для проведения анализа.

Для того чтобы отчетность выступала эффективным инструментом управления устойчивостью деловых отношений она должна содержать информацию, которая интересует стейкхолдеров и связанными с ней рисками.

C учредителями, управленческим персо- налом и сотрудниками при высоких вероятностях взаимодействия и угрозы рекомендуется придерживаться стратегии взаимодействия. С учредителями могут быть следующие методы взаимодействия: переговоры, переписки и запросы, представление презентаций. Для управленческого персонала можно создавать рабочие группы и проводить оперативные совещания. Сотрудникам предоставлять возможность профессионального роста, проводить анкетирование и опросы и так далее.

С помощью матрицы зрелости можно провести оценку уровня зрелости устойчивого развития, определить текущее состояние организации, а также установить ключевые направления деятельности, в рамках которых компании следует совершенствоваться и развиваться. Формирование этой матрицы основывается на установленных целях организации в области устойчивого развития и разработке плана действий по их воплощению.

Значения реализации практик устойчивого развития свидетельствуют о том, что самый высокий уровень зрелости имеют принципы «Соблюдение этических норм» в практике ключевых способов взаимодействия и «Ответственное руководство».

Принцип «соблюдение этических норм» достиг среднего (ближе к высокому) уровня зрелости устойчивого развития. Для достижения такого уровня ООО «АБС» стремится соответствовать самым высоким стандартам этичного ведения бизнеса. Осознавая важность работы для здоровья и благополучия людей, первоочередное внимание уделяется тому, чтобы все сотрудники понимали ценности компании, положения Кодекса корпоративной этики, политик и процедур, а также общие юридические обязательства. В ООО «АБС» созданы все условия для открытых и доверительных отношений и укрепления культуры этичного поведения в компании. Обучающие и образовательные программы призваны повысить осведомленность сотрудников о Кодексе корпоративной этики компании, а также юридических и этических последствиях их повседневных действий и поведения. Сотрудники также могут сообщить о предполагаемых нарушениях Кодекса, политик или процедур путем обращения в службу поддержки по вопросам соблюдения корпоративной этики. Средний уровень зрелости достигнут по принципу «вовлеченность». У компании существует понима- 
ние значимости заинтересованных сторон для бизнеса, но нет четкого определения ключевых стейкхолдеров.

По принципу «ответственного руководства» ООО «АБС» достигла высокого уровня зрелости. Компания поощряет и стимулирует развитие каждого сотрудника, предлагая благоприятные условия для построения успешной карьеры, личного роста и развития. В ООО «АБС» созданы равные для всех сотрудников возможности независимо от пола, возраста, национальности. Индивидуальность каждого сотрудника, их опыт, навыки, взгляды рассматривается как важный фактор успешной конкуренции на рынке. Уникальность каждого члена команды важна для повышения эффективности компании на всех уровнях. Также ООО «АБС» старается делать все возможное, чтобы снизить свое воздействие на окружающую среду. Утилизация отходов является серьезной проблемой в России.

Реализация принципа «прозрачность» находится на среднем уровне. Так, ООО «АБС» составляет бухгалтерскую (финансовую) отчетность и уделяет особое внимание разделу корпоративной социальной ответственности. Информация КСО публикуется на сайте, но отчета по ней не формируется. Таким образом, уровень зрелости устойчивого развитии компании ООО «АБС» можно охарактеризовать как средний. Компания уделяет достаточное внимание некоторым аспектам устойчивого развития, но не наблюдается четких поставленных целей и задач в этой области.

Неотъемлемой частью стратегии развития бизнеса, создания положительной репутации и повышения уровня конкурентоспособности является корпоративная социальная ответственность, которая в свою очередь вызывает большой интерес стейкхолдеров компании. Поэтому ООО «АБС» необходимо выстраивать гибкую политику внедрения мероприятий, направленных на тесное взаимодействие с заинтересованными сторонами.

Так как корпоративная социальная ответственность играет важнейшую роль при принятии управленческих решений в ООО «АБС», в качестве стратегии компании предложены следующие мероприятия: вовлечение заинтересованных сторон; развитие сотрудников.

Реализация мероприятий в области корпоративной социальной ответственности может стать ключевым аспектом успеха компании и эффективным способом развития компании в целом. КСО может послужить неким импульсом к созданию привлекательного имиджа ООО «АБС» для всех стейкхолдеров, посредством выстраивания производственной культуры бизнеca.

Деятельность любой организации всегда динамична в период её существования. Большая часть динамических процессов характеризируется либо ростом, либо развитием. Рост -увеличение масштабов бизнеса (рост стоимости, доли рынка, объемов реализации). Развитие - это качественное изменение (выход на новые рынки, изменение технологии производства, обеспечивающее долгосрочное конкурентное преимущество). Измерителями экономического роста могут выступать следующие показатели: рост выручки, рост прибыли, рост стоимости бизнеса.

В современных условиях любая организация стремится к развитию, которое позволило бы ей сохранить и приумножить свое конкурентное преимущество и расширить свою долю рынка. Поэтому устойчивый рост и развитие становятся стратегической целью. Также разработаны концепции для оценки устойчивости экономического роста организации. Концепция устойчивого развития на уровне экономических субъектов предполагает необходимость взаимосвязанного рассмотрения экологической, социальной и экономической сфер деятельности организации (ESG). Концепция устойчивого развития связана с рядом управленческих концепций, которые получили широкое применение в практике корпоративного контроля. В том числе стейкхолдерская концепция, концепция корпоративной социальной ответственности.

Для создания основы устойчивого развития бизнеса необходимо проводить постоянный комплексный анализ всех воздействующих на компанию факторов и оценивать их воздействие на развитие предприятия. Устойчивым может быть экономический рост, рассматриваемый в единстве с экологическими и социальными аспектами. Поэтому факторы, обеспечивающие устойчивость экономического роста организации, должны рассматриваться вместе с факторами устойчивого развития.

Исследуемой организацией в данной работе выступило общество с ограниченной ответственностью «АБС», которое осуществляет оптовую торговлю фармацевтическими препаратами. Компания занимает 0,2864\% (5,08 млрд. 
руб.) рынка страны «Торговля оптовая фармацевтической продукцией». Общий объем рынка составляет 1.77 трлн. руб., за 2019 год. ООО «АБС» - международная фармацевтическая компания. На протяжении многих лет ООО «АБС» успешно разрабатывает эффективные методы помощи пациентам в разных областях.

Диагностика ESG-факторов устойчивого развития организации позволила оценить степень раскрытия информации экономической, социальной и экологической темы в соответствии со стандартами отчетности в области устойчивого развития GRI Standards. Также было выявлено, что корпоративная социальная ответственность играет важнейшую роль при принятии управленческих решений в компании и является неотъемлемой частью всей деятельности, помимо этого ООО «АБС» осуществляет реализацию многочисленных социальных программ.

Анализ финансовой устойчивости по абсолютным показателям характеризирует финансовое состояние ООО «АБС» за 2018-2019 гг. как абсолютно устойчивое. Запасы покрываются собственными оборотными средствами, что может говорить о высокой платежеспособности и отсутствии зависимости от кредиторов. Анализ относительных показателей финансовой устойчивости свидетельствует о том, что в динамике за период 2018-2019 гг. финансовое положение ООО «АБС» улучшается. Все показатели находятся в пределах нормы.

Анализ деловой активности организации по «золотому правилу экономики» показал, что в ООО «АБС» увеличились издержки, выросла эффективность использования ресурсов, повысилась отдача с каждого рубля, вложенного в организацию, и произошло сокращение активов и капитала. Исследование относительных показателей позволило сделать вывод о том, что в це- лом деловая активность ООО «АБС» в 2019 году снизилась по сравнению с предыдущим годом.

При проведении анализа финансовой результативности было выявлено ее снижение в 2019 году, об этом свидетельствует сокращение всех анализируемых коэффициентов рентабельности. Также произошло снижение прибыли от продаж в 2019 году, это обуславливается превышением темпов роста себестоимости реализуемой продукции (работ, услуг) над темпами роста выручки от их реализации, даже несмотря на сокращение накладных расходов.

Коэффициент устойчивого развития снизился наибольшее влияние оказало сокращения значения рентабельности продаж. Соответственно, на основании этого факта можно сделать вывод, что для обеспечения экономического роста в долгосрочной перспективе необходимо увеличивать объем продаж и снижать себестоимость. Для сокращения себестоимости необходимо ввести комплекс мероприятий по более рациональному использованию материальных ресурсов, в частности направленных на сокращение энергопотребления.

В завершении данной работы были обозначены заинтересованные стороны ООО «АБС», определен их уровень взаимодействия с компанией. Также был проведен анализ зрелости устойчивого развития ООО «АБС», его результаты показали, что компания достигла, по определенным принципам, среднего уровня зрелости.

В силу того, что ООО «АБС» небольшая компания, ей был предложен комплекс стратегических мероприятий для реализации в рамках КСО. Результаты данных мероприятий рекомендуется отразить в моноотчете «Социальная ответственность», таким образом стать на шаг ближе к реализации концепции устойчивого развития.

\section{Библиографический список}

1. Гражданский кодекс Российской Федерации (часть первая) от 30.11.1994 № 51-ФЗ (ред. от 16.12.2019) // СПС Консультант плюс.

2. Федеральный закон от 08.02.1998 N 14-ФЗ (ред. от 04.11.2019, с изм. от 07.04.2020) «Об обществах с ограниченной ответственностью»

3. Указ Президента РФ от 01.04.1996 № 440 «О Концепции перехода Российской Федерации к устойчивому развитию»

4. Распоряжение Правительства РФ от 05.05.2017 № 876-р «Об утверждении Концепции развития публичной нефинансовой отчетности и плана мероприятий по ее реализации»

5. ГОСТ Р 54598.1-2015. Национальный стандарт Российской Федерации. Менеджмент устойчивого развития. Часть 1. Руководство» (утв. и введен в действие Приказом Росстандарта от 18.11.2015 № 1858-ст) 
6. Бариленко В.И. Аналитическое обоснование конкурентоспособных бизнес-моделей: учебное пособие / В. И Бариленко, В.В.Бердников, О.Ю. Гавель, Ч.В. Керимова; под ред. проф. В.И.Бариленко.- М.: РУСАЙНС, 2017. -308 c.

7. Бариленко В.И. Экономический анализ: учебник для студ. вузов, обуч. по напр. «Экономика» / В.И.Бариленко [и др.]; Финуниверситет; под ред. В.И. Бариленко.- Москва: Кнорус, 2017. - 382 с.

8. Зенкина И.В. Методические подходы и инструменты анализа устойчивого развития организации // Экономический анализ: теория и практика.-2019.- Т. 18, № 9.- С. 1667-1686.

9. Качкова О.Е. Экономический анализ хозяйственной деятельности: учебник / О. Е. Качкова, М.В. Косолапова, В.А. Свободин.- Москва: КНОРУС, 2020. - 360 с.

10. Никифорова Н.А. Комплексный экономический анализ: учебник / НикифороваН.А.- Москва: КноРус, 2021.-439 c.

11. Справочная правовая система «КонсультантПлюс» - URL: http://www.consultant.ru 